\title{
Investigation of Radioactive Element in Broiler Feeds Using Nuclear Technique
}

\author{
MS Anas* and Abdullahi Sulaiman \\ CAAS Mando, Division of Agricultural Colleges, Ahmadu Bello University, Nigeria
}

Submission: July 14, 2017; Published: September 15, 2017

*Corresponding author: Abdullahi Sulaiman, Division of Agricultural Colleges, Ahmadu Bello University, Zaria, Nigeria, Tel: +234 8062883863 ;

Email: abuumair399@gmail.com

\begin{abstract}
The experimental techniques Neutron Activation Analysis (NAA) was used to evaluate the concentration of radioactive element in broiler feeds. In this process the concentration of 19 elements (Mg, Mn, Na, Rb, V, Sr, Br, Ca, Sm, Cl, Co, Cr, Fe, Th, K, Sb, Sc, La and Zn) were evaluated. The samples with name (BRF A, BRF B, BRF C, and BRF D) represents certain brand of the feeds where irradiated by short and long protocols, with thermal flux of $5.0 \times 1011 \mathrm{ncm}-2 \mathrm{~s}-1$. The result shows that the radioactive elements in the samples BRF C and BRF Dare virtually Below Detection Limit (BDL). Even though small concentration of Thorium (Th-229) which has half-life of $7.54 \times 104$ years $(0.06 \pm 0.02 \mathrm{ppm}$ and $0.07 \pm 0.01 \mathrm{ppm})$ $(\mu \mathrm{g} / \mathrm{g})$ was observed in sample BRF A and BRF B and concentration of Fe in sample BRF B and Zn in sample BRF C and BRF D were found to exceed the maximum acceptable limit. The result will serve as close monitoring of feed contamination by governments and environmentalist since radioactive elements have the tendency to be transferred to human after consumption
\end{abstract}

Keywords: Neutron activation analysis (NAA); Radioactive elements

\section{Introduction}

Since radioactivity was first discovered, there has been concern regarding the damage that it might pose to humans, living creatures and the environment. Many studies have been dedicated to monitoring amounts of radionuclides' activity in food and nutritional supplements, particularly related to the human diet, seeking to determine the risks those amounts may bring [1-3].

Measured feeds were all developed from a base of soy, wheat, corn fibers, sodium chloride and a vitamin complex called ("Vitamin Mineral Premix"). Thus, in these feed samples one must account for the natural radioactivity present in corn, wheat and soy, for example. Plants are primary receivers of radioactive contamination. The absorption of radionuclides from soil depends not only on their physiology but also in the processes that occur in there [4]. However, due to the difference in mobility of Radium and Uranium, as published by [5] one should not expect radioactive equilibrium in natural series in biological samples and processed geological materials. Since radionuclides that are after 226Ra and 228Ra in their respective chains were measured in the present work, it was possible to estimate the activity of 226Ra in the Uranium series, and the activity of 228Ra and 228Th in the Thorium series. Phosphorous is one of the elements often added to feed, since it is one of the most important minerals for living organisms, including humans. It impacts several important biological processes, such as the osmotic pressure and all metabolic reactions $[6,7]$. For this reason, concern with radiation levels in feed and samples is also very important, once ingestion is one of the most common ways radionuclides enter living organisms. Thus, as humans ingest both eggs and poultry, milk and beef, it is relevant to monitor the radiation levels in animal feed samples since a part of the radioactivity to which these animals are exposed could possibly be transferred to humans.

Poultry farming is one of the most important aspect of agriculture with commercial layers and broilers contributing tremendously in meeting the upward protein demand of the increasing population through eggs and meet supplementation of some essential metals such as copper ( $\mathrm{Cu})$, Zinc $(\mathrm{Zn})$ and Manganese (Mn) in chicken diet is of great importance to humans. Even though transitional metals such as Nickel with an atomic structure very similar to that of Cobalt which is not normally added to chicken diets, but has been detected in Liver, Kidney and Muscle of broilers [8-10]. Radioactive element and Heavy metals are ubiquitous and are being released continuously from man-made sources into the aquatic and terrestrial ecosystems, 
threatening the health of man and animals [11-12]. They are potentially dangerous due to their toxicity bioaccumulation abilities when found within living tissue and are stored more quickly than they are excreted.

Owing to the rapid increase in development of intensive animal farms in the world, animal manure production is greater than $32 \times 108$ it annually [13]. Commonly, animal manure was applied to agricultural land to improve the soil fertility and organic matter content. However, this practice also results in serious environmental problems, such as nitrate and phosphate contamination of surface waters [14,15]. Another important problem induced by the animal manure application is metal pollution, as animal manure contains high metal (Cu, Zn, As, Cd) concentrations [16]. Residues of heavy metals in manures can be accumulated in surface soils as a result of long-term agricultural use [17]. Accumulation of heavy metals could not only affect the soil fertility and the product quality $[18,19]$, but also promote metal migration through leaching and runoff [20]. Therefore, due to potential risks of heavy metal pollution, heavy metal residues in animal manure have received scientific attention [21]. A wide range of heavy metals in animal manures has been investigated in intensive animal production in the world [22-24].

It was confirmed that animal manure was an important source of soil pollution caused by heavy metals in [25] suggested that the application of manure would enhance the risk of $\mathrm{Cu}$ contamination In recent years, the economic boom has stimulated the demand for animal products and consequently led to a vast expansion of animal production. It is a common practice to add minerals such as copper ( $\mathrm{Cu}$ ), zinc ( $\mathrm{Zn}$ ) and arsenic (As) to animal feeds via mineral additives because of their antimicrobial and growth-stimulating effects [26-29]. However, so far, the impacts of feed additives application and heavy metals residue in animal manures in the Northern Nigeria remain unknown. In this study, for the convenience of constructing more accurate metal budgets and calculating the average rates of heavy metal inputs in agricultural land, we sampled animal feeds and manures from animal farms of different scales to determine the contents of heavy metals in this area.

Among the pollutants generated by various industrial, domestic and commercial sewerage effluents, radiological metals and heavy metals are directly related to the health problems. Health safety is very important aspect of food quality. Hazardous substances enter the food chain and are the main sources of contamination for humans. These metals are most dangerous contaminants. Radiological metal and Heavy metals poisoning results from contamination of drinking water (e.g. lead pipes) or intake through food chain. Heavy metals are dangerous because they tend to accumulate inside the living organisms. These are found everywhere in nature [30]. These contaminants pollute air, rivers, canals and underground water resources. These contaminants consist of a large variety of biological and chemical agents of diseases. The most dangerous metals contaminants are lead, cadmium, and mercury and entrance of these toxic metals to human body results in various harmful diseases. The concept for healthy food is that it should be free from all types of health hazards and having good taste. From above discussion it is estimated that the main source of heavy metals toward human body is food and one of the important food item is Chicken meat. This give us a clue that Extensive research on the study of radioactive element and heavy metal content in broiler feeds using Neutron Activation Analysis (NAA) should be carried out which is our hope at the end of this research.

\section{Material and Method}

\section{Materials}

The materials required for the experiment are: Reactor for irradiation, Distil water, HPGe detector, samples for analysis, analytical balance, Glove, Cylinder vials, laboratory agate and mortar, cotton wool, acetone sieve, white papers, forceps spatula.

\section{Method}

In the process of NAA the neutrons interact with the stable isotopes of the target element converting them to radioactive ones. The so-called compound nucleus emits gamma rays promptly with extremely short half-lives and these can be measured during irradiation through a technique called Prompt Gamma Activation Analysis (PGAA). In most cases, the radioactive isotopes decay and emit beta particles accompanied by gamma quanta of characteristic energies, and the radiation can be used both to identify and accurately quantify the elements of the sample. In the process of NAA the neutrons interact with the stable isotopes of the target element converting them to radioactive ones. The so called compound nucleus emits gamma rays promptly with extremely short half lives in the order of $\mathrm{ms}$ and these can be measured during irradiation through a technique called Prompt Gamma Activation Analysis (PGAA). In most cases, the radioactive isotopes decay and emit beta particles accompanied by gamma quanta of characteristic energies, and the radiation can be used both to identify and accurately quantify the elements of the sample [31].

In this research the following steps are to be followed to achieve correct result: [32].

Sample preparation means in most cases only pulverising, homogenising, mass determination, packing, as well as the selection of the best analytical process and the preparation of the standards, if any. The first step in sample preparation is identification of the sample, if it is in granulated form, it should be crushed with mortar and pestle. If powdery, it must be homogenous as possible. The steps for crushing a granulated sample and their apparatus are:

a. Hand gloves were worn to avoid contamination of the sample, mortar and pestle are washed with water and then clean with acetone to avoid contamination. 
b. Acetone or water was not used to clean the sieving materials are made up of brass instead of a brush was used.

c. A white sheet of paper was spread in order to put the sample after crushing.

d. After each sample a new glove were worn to avoid contamination of the samples.

e. Weigh the samples into polyethylene bags using analytical balance. The standard range of weight required for biological samples it ranges from $0.25 \mathrm{~g}$ to $0.50 \mathrm{~g}$. But due to complex nature of sample we are dealing with, the actual mass of the sample is divided into two i.e 0.125 due to the activity, decay time and half lives of the element expected in the samples.

f. The polythene was cut into a bag like form for packaging.

g. The polyethylene films and rabbit capsules were cleaned by soaking in 1:1 concentrated HNO3 for 3 days and washed with de-ionized water in the NIRR-1 laboratory. Blank concentrations of all the elements of interest will be investigated.

h. After this time, the vials and nylon are removed and washed in distilled water two to three times. Then the vials and nylon are put in an oven for dryness. The oven was operated at $60^{\circ} \mathrm{C}$ for $1 \mathrm{hr}$ or $50^{\circ} \mathrm{C}$ for $2 \mathrm{hrs}$.

In this work, standard samples prepared in-house (NIST 1515 ) in order to certified result.For the irradiation of the samples, two schemes will be adopted based on the half-life of product radio nuclide. For the elements leading to short-lived activation products the samples are each packed and sealed in $7 \mathrm{~cm} 3$ rabbit capsules and was send for irradiation in an outer irradiation channel B4 of NIRR-1 which is capable of eliminate corrections due to nuclear interferences caused by threshold reactions and where the neutron spectrum is 'soft'. This is due to the proximity of the innerchannels of MNSR to the core which may lead to a relatively higher ratio of fast-to-thermal neutrons. For long-lived activation products, samples will follow a similar procedure as the short-lived except for irradiation time. Samples will be irradiated for $6 \mathrm{~h}$ in any of the NIRR-1 inner irradiation channels B1 or B2 or B3 to take the advantage of the maximum value of thermal neutron flux in the innerchannels since the previous HEU core.

Radioactivity measurement of induced radio nuclides will be carried out by the PC-based gamma-ray spectrometry setup. Following the short-live irradiation regime, the neutron flux setting was raised to $5^{*} 1011 \mathrm{n} / \mathrm{cm} 2 \mathrm{~s}$ for biological samples in order to increase the detection sensitivities for analysis of elements using procedures S1 and S2. The counting scheme for HEU core will adopted, where by the first of the activated sample will be counted for $10 \mathrm{~min}$ (S1) after a waiting time of 2-15min. Samples will be place on a glass sample holder "H2" which corresponds to source-detector geometry of $5 \mathrm{~cm}$. The second round of counting will also be carried out for $10 \mathrm{~min}$, following the short-live irradiation regime (S2) after a waiting period of 3-4 h. Samples will be counted on a glass holder "H1" corresponding to a source-detector geometry of $1 \mathrm{~cm}$. With respect to the longlive irradiation regime, the first round of counting will be carried out for $30 \mathrm{~min}$, following the long-live irradiation (L1) using the holder 'H1' after a waiting period of 4-5 days. Similarly the second round of counting will be for $60 \mathrm{~min}$ (L2) after a cooling time of 10-15 days using the glass holder "H1". According to Jonah et. al., 2006 the choice of cooling time and sample-detector geometry is such that detector's dead time is controlled to be less than $10 \%$. Identification of gamma-ray of product radionuclides through their energies and quantitative analysis of their concentrations are achieved using the gamma-ray spectrum analysis software, WINSPAN 2004.

\section{Result and Discussion}

Table 1: Shows list of broiler feeds analyzed for radioactive element, and concentration in part per million (ppm or $\mu \mathrm{g} / \mathrm{g}$ ). The reported uncertainty was calculated mainly from counting statistic and is not normal standard deviation on replicate analyses. The results obtained from the elemental analysis of the selected broiler feeds are presented and it shows the concentrations of elemental content in the sample BRF A, BRF B, BRF C and BRF D.

\begin{tabular}{|c|c|c|c|c|}
\hline \multirow[t]{2}{*}{$\mathbf{C}$} & \multicolumn{2}{|c|}{ Concentration in PPM } & \multirow[b]{2}{*}{ BRF C } & \multirow[b]{2}{*}{ BRF D } \\
\hline & BRF A & BRF B & & \\
\hline $\mathrm{Mg}$ & $5161 \pm 279$ & $5320 \pm 96$ & $3678 \pm 169$ & $3839 \pm 342$ \\
\hline $\mathrm{Al}$ & $961 \pm 22$ & $436 \pm 10$ & $325 \pm 12$ & $130 \pm 8$ \\
\hline $\mathrm{Cl}$ & $4615 \pm 46$ & $1790 \pm 30$ & $4773 \pm 81$ & $2328 \pm 51$ \\
\hline $\mathrm{Ca}$ & $13340 \pm 494$ & $9543 \pm 382$ & $6501 \pm 533$ & $5614 \pm 438$ \\
\hline $\mathrm{V}$ & $59 \pm 17$ & BDL & $63 \pm 13$ & $\mathrm{BDL}$ \\
\hline Mn & $320 \pm 2$ & $58.1 \pm 0.3$ & $125.2 \pm 0.9$ & $143.4 \pm 0.9$ \\
\hline $\mathrm{Sr}$ & $212 \pm 25$ & $74 \pm 9.3$ & BDL & BDL \\
\hline $\mathrm{Na}$ & $1294 \pm 3$ & $683.4 \pm 2.1$ & $1443 \pm 3$ & $1402 \pm 2.8$ \\
\hline $\mathrm{K}$ & $13570 \pm 68$ & $17980 \pm 90$ & $10440 \pm 167$ & $17360 \pm 156$ \\
\hline $\mathrm{La}$ & $10.9 \pm 0.01$ & $0.79 \pm 0.08$ & $0.17 \pm 0.03$ & BDL \\
\hline
\end{tabular}




\begin{tabular}{|c|c|c|c|c|}
\hline $\mathrm{Sm}$ & $1.91 \pm 0.01$ & $0.123 \pm 0.006$ & $0.018 \pm 0.005$ & BDL \\
\hline Sc & $0.068 \pm 0.009$ & $0.12 \pm 0.01$ & $0.08 \pm 0.01$ & $0.037 \pm 0.008$ \\
\hline $\mathrm{Cr}$ & BDL & BDL & BDL & BDL \\
\hline $\mathrm{Fe}$ & $409 \pm 47$ & $718 \pm 47$ & $333 \pm 31$ & $113 \pm 24$ \\
\hline Co & $0.061 \pm 0.012$ & $0.07 \pm 0.02$ & $0.09 \pm 0.01$ & $0.082 \pm 0.020$ \\
\hline $\mathrm{Zn}$ & $42.4 \pm 3.6$ & $41.2 \pm 4.4$ & $117 \pm 5$ & $95 \pm 5$ \\
\hline $\mathrm{Br}$ & $1.450 \pm 0.416$ & $5.1 \pm 0.6$ & $2.9 \pm 0.7$ & $8.11 \pm 0.71$ \\
\hline $\mathrm{Rb}$ & $23.2 \pm 1.6$ & $17.6 \pm 1.5$ & $16.1 \pm 1.5$ & $13.6 \pm 1.4$ \\
\hline $\mathrm{Ba}$ & $320 \pm 20$ & $105 \pm 11$ & BDL & $41.5 \pm 11.3$ \\
\hline Th & $0.06 \pm 0.02$ & $0.07 \pm 0.01$ & BDL & BDL \\
\hline
\end{tabular}

Since radioactivity was first discovered, there has been concern regarding the damage that it might pose to humans, living creatures and the environment. Many studies have been dedicated to monitoring amounts of radionuclides' activity in food and nutritional supplements, particularly related to the human diet, seeking to determine the risks those amounts may bring. Even though in poultry feed reference standard prepared by the Standard Organization of Nigeria (SON), there are requirement of some essential trace metals mentioned as micronutrient but no standard as a contaminant in terms of maximum acceptable limit for the radioactive element was mentioned. Copper, zinc, manganese and iron which are heavy metals are included in the requirement as micro-nutrient Table 1.

In this research we based our discussion on the radioactive and heavy elemental content of the samples considering the maximum acceptable limit as follows:

a. Iron $(\mathrm{Fe})$ was found in all samples but above the permissible level $45-80 \mu \mathrm{g} / \mathrm{g}$ as stipulated by and comparing with that of which will suffice the nutritional requirement of the poultry [33].

b. Zinc ( $\mathrm{Zn})$ concentration was found to be highest in the sample BRF C followed by sample BRF D, BRF A and BRF B respectively. It was observed that the concentration of zinc in a samples BRF A and BRF B, were within the permissible limit of $10-50 \mathrm{ppm}(\mu \mathrm{g} / \mathrm{g})$, while the concentration in samples BRF C and BRF D is above the permissible limit set by [1]. In general, zinc level were found in samples BRF A and BRF B to be within the permissible limit as stipulate by European Union.

The table shows the concentration of Thorium (Th-229) of with value of $(0.06 \pm 0.02 \mathrm{ppm}$ and $0.07 \pm 0.01 \mathrm{ppm})(\mu \mathrm{g} / \mathrm{g})$ in sample BRF A and BRF B respectively, meanwhile the concentration Thorium (Th-229) of in samples BRF C, and BRF D, is Below Detection Limit (BDL). This shows that the sample that have fraction of thorium is not recommended because thorium is radioactive element, since radioactive elements have the tendency to be transferred to human after consumption.
The Mn concentration in all the samples shows that Mn was present in all the feed analyzed. Mn is an important element to the animal body. Manganese which is also a micro-nutrient mentioned by SON at $50-60 \mu \mathrm{g} / \mathrm{g}$. It was found that, all the feed samples are above the micro requirement except sample BRF B. The concentrations of Cobalt Co have range value of $(0.07 \pm 0.02$ to $0.082 \pm 0.02$ ) ppm in all the samples with Copper $\mathrm{Cu}$, Selenium $\mathrm{Se}$, and $\mathrm{Cr}$ in the entire sample were found to be Below Detection Limit (BDL), even though some of them have little importance in the feed and animal body.

The results revealed that the selected broiler feeds accumulate these elements at different concentrations. Monitoring such broiler feed for radioactive elements concentration is of great importance for policy makers in protecting the public, physicians and health care professionals from the adverse effects of this radioactive element. Therefore, extra measures need to be taken in order to eliminate/reduce the heavy metals from entering the feeds there by reducing human exposure through feeding and there should be provision by Standard Organization Nigeria to provide maximum acceptable limit for radioactive element not only for the micro minerals.

\section{Conclusion}

In this research, four (4) different samples of broiler feed were purchase from different area of Kaduna state of Nigeria to analyze the radioactive element composition using Neutron Activation Analysis (NAA). The result shows that all the macronutrient among the analysed sample presence are $\mathrm{Ca}, \mathrm{K}, \mathrm{Cl}$, $\mathrm{Mg}$ and $\mathrm{Na}$ which significant amount. Other element present are $\mathrm{Fe}, \mathrm{Mn}$, and $\mathrm{Zn}$ are above the permissible limit in all the samples. This makes the samples not recommended for animals due to bio accumulation toxic and heavy element. The remaining were at below 1\% or Below Detection Limit (BDL) except for radioactive element Thorium (Th-229) of with value of $(0.06 \pm 0.02 \mathrm{ppm}$ and $0.07 \pm 0.01 \mathrm{ppm})(\mu \mathrm{g} / \mathrm{g})$ in sample BRF A and BRF B respectively. However the concentration of radioactive element in sample BRF C and BRF D is below detectable limit, which shows that the sample with Thorium (Th-229) some level of radioactivity toxicity compare to the other samples. The levels of the entire 
studied element were within the tolerance limit except Fe and $\mathrm{Zn}$ in some sample. In general there is the need to also increase the quantity of supplements been added to the feeds so as to increase its nutritional values for the poultry feed. We have demonstrated in this study that Neutron Activation Analysis NAA method is ideal for determination of radioactive element and heavy metals in broiler feed. Since the technique is a non-destructive one and requires no sample dissolution.

\section{Acknowledgment}

The Authors wish to acknowledge the cooperation and assistance of the NIRR-1 operation and utilization group during the experimental work. Profound gratitude to the former Director of Division of Agricultural colleges in person of Prof. Fatihu M. Yakasai whom without him this work cannot be achieved.

\section{References}

1. IAEA (1994) Handbook of Parameters Values for the Prediction of Radionuclide Transfer in Temperate Environments Technical Report Series No. 364. International Atomic Energy Agency, Vienna.

2. IAEA (2003) Guidelines for radioelement mapping using gamma ray spectrometry data, Technical Report Series No. 1363. International Atomic Energy Agency, Vienna, Austria.

3. Ramli AT, Apriantoro NH, Wagiran H, Wood AK, Kuan SL (2009) Health Risk Implications of High Background Radiation Dose Rate in Kampung Sungai Durian, Kinta District, Perak, Malaysia. Global Journal of Health Science 1(2): 140-149.

4. United Nations Scientific Committee on the Effects of Atomic Radiation (2000) Sources and effects of ionizing radiation. UNSCEAR 2000. Report to General Assembly. United Nations.

5. Kapsimalis R, Landsberger S, Ahmed YA (2009) The determination of uranium in food samples by Compton suppression epithermal neutron activation analysis. Appl Radiat Isot 67(12): 2097-2099.

6. Mazzilli B, Palmiro V, Saueia C, Nisti MB (2000) Radiochemical Characterization of Brazilian Phosphogypsum. Journal of Environmental Radioactivity 49: 113-122.

7. Radwan MA, Salama AK (2006) Market basket survey for some heavy metals in Egyptian fruits and vegetables. Food Chem Toxicol 44(8): $1273-1278$

8. Anas MS, Ahmed YA, Yusuf JA (2016) Determination of Trace and Heavy Metals in Selected Nigeria Broiler Feeds by Neutron Activation Analysis (NAA). J Nucl Ene Sci Power Generat Technol 5(3).

9. Mousa A. Mohammed, Shakir M Al-Jobori, Firas M Hadi (2006) Determination of Toxic and Trace Elements in The Milk By Using X-Ray Fluorescence Technique. AL-fateh, journal, No27.

10. Surtipanti S, Suwirma S, Yumiarti S, Yune Mellawati (1990) Determination of Heavy Metals in Meat, Intestine, Liver, Eggs, and Chicken Using Neutron Activation Analysis and Atomic Absorption Spectrometry. Center for the Application of Isotopes Radiation, BATAN.

11. Donaldson MS (2004) Nutrition and cancer: a review of the evidence for an anti-cancer diet. Nutr J 3: 19

12. Anas MS, Nuhu A, YusufJA (2016) Assessment of Elemental Composition in Selected Nigeria Broiler Feeds Using Neutron Activation Analysis (NAA). J Vet Sci Med Diagn 5(3).
13. Soete D, Gijbels R, Hoste J (1972) Neutron Activation Analysis. Wiley Interscience, New York.

14. Avegliano RP, Maihara VA, da Silva FF (2008) Total diet study in the state of São Paulo, Brazil, to estimate the dietary intakes of toxic and essential elements: development of the Market Basket. Ciênc Tecnol Aliment 28(1): 90-97.

15. Martinez-Aguirre A, García-Le n M (1997) Radioactive impact of phosphate ore precessing in a wet marshland in southwestern Spain. Journal of Environmental Radioactivity 34(1): 45-57.

16. Kira CS, Maihara VA (2007) Determination of major and minor elements in dairy products through inductively coupled plasma optical emission spectrometry after wet partial digestion and neutron activation analysis. Food Chemistry 100(1): 390-395.

17. Oladipo MOA (2003) Establishment of Geological References Materials from Clay Sources: Comparison of Results obtained from Collaborating Laboratories, Centre for Energy Research and Training CERT Zaria. University Press Zaria.

18. IAEA (1989) Measurements of radionuclides in food and the environment Technical Reports Series, 295. International Atomic Energy Agency, Vienna.

19. Vértes A, Nagy S, Süvegh K (Eds.) (1998) Nuclear Methods in Mineralogy and Geology. Techniques and Applications Plenum Press, NewYork and London.

20. Gäfvert T, Holm E, Roos P (2001) Radionuclide fluxes at a plant manufacturing dicalcium phosphate for domestic animals. J Environ Radioact 54(1): 61-73.

21. VA Maihara, IB Gonzaga, VL Silva VL, DIT Fávaro, MBA Vasconcellos, et al. (2004) Daily dietary selenium intake of selected Brazilian population groups. Journal of Radioanalytical and Nuclear Chemistry 259(3): 465-468.

22. Rutherford PM, Dudas MJ, Arocena JM (1996) Heterogeneous distribution of radionuclides, barium and strontium in phosphogypsum by-product. Science of the Total Environment 180(3): 201-209.

23. IAEA (2007) Worldwide Open Proficiency Test on the Determination of Radionuclides in Spinach, Soil and Water. IAEA Analytical Quality in Nuclear Applications Series No. 8 (IAEA-CU-2007-03) International Atomic Energy Agency, Vienna.

24. Parekhan Aljaff, Banaz O Rasheed, Dler M Salh (2014) Assessment of heavy metals in livers of cattle and chicken by spectroscopic method. IOSR Journal of Applied Physics (IOSR-JAP) e-ISSN: 2278-4861 6(1): 23-26.

25. Azouazi M, Ouahidi Y, Fakhi S, Andres Y, Abbe JC, et al. (2001) Natural radioactivity in phosphates, phosphogypsum and natural waters in Morocco. J Environ Radioact 54(2): 231-242.

26. Scheibel V, Appoloni CR, Schechter H (2006) Natural radioactivity traces in South-Brazilian cereal flours by gamma-ray spectrometry. Journal of Radioanalytical and Nuclear Chemistry 270(1): 163-165.

27. Zagato VAB, Medina NH, Okuno E, Umisedo NK (2007) Natural Radiactivity in Bananas. $8^{\text {th }}$ International Symposium (NRE VIII) AIP Conference Proceedings 1034, pp. 264-268.

28. Saueia CH, Mazzilli BP, Fávaro DIT (2005) Natural radioactivity in phosphate rock, phosphogypsum and phosphate fertilizers in Brazil. Journal of Radioanalytical and Nuclear Chemistry 264(2): 445-448.

29. Saueia CH, Mazzilli BP (2006) Distribution of natural radionuclides in the production and use of phosphate fertilizers in Brazil. J Environ Radioact 89(3): 229-239. 
30. Anas MS, Abdullahi S, Yusuf JA, Bala B, Salihu YB (2015) Assessment of toxic elements in selected Nigeria broiler feeds using neutron activation analysis (NAA) Bayero Journal of Pure And Applied Sciences 8(2): 166-169.

31. Maihara VA, Fávaro DIT, Silva VN, Cunha IIL, Vasconcellos MBA et al. (2001) Analysis of mineral constituents in duplicate portion diets of two university student groups by instrumental neutron activation analysis. J Radioanal Nucl Chem 249(1): 21-24.
32. Khalid N, Rahman S, Ahmad S, Ali S (2007) Trace Metals Determination In Chicken Eggs The Nucleus 44(1-2): 39-44 J.L. Gerberding, Toxicological Profile forzinc. Atlanta Georgia.2005, PP 22 and 23J.H. koplan, Atlanta Georgia, 2000a, 26P.

33. Silva NC, Piracicaba SP, Cipriani M, Taddei MHT, Fernandes EAN (2001) The natural radioactivity of Brazilian phosphogypsum. Journal of Radioanalytical and Nuclear Chemistry 249(1): 251-255.

This work is licensed under Creative Commons Attribution 4.0 Licens

DOI: 10.19080/JDVS.2017.03.555617

\section{Your next submission with Juniper Publishers} will reach you the below assets

- Quality Editorial service

- Swift Peer Review

- Reprints availability

- E-prints Service

- Manuscript Podcast for convenient understanding

- Global attainment for your research

- Manuscript accessibility in different formats

( Pdf, E-pub, Full Text, Audio)

- Unceasing customer service

Track the below URL for one-step submission https://juniperpublishers.com/online-submission.php 